\section{Characterization of 'Castellana' Virgin Olive Oils with Regard to Olive Ripening}

\author{
Carmen Mena, Alejandra Z. González, Raúl Olivero-David, \\ and María Ángeles Pérez-Jiménez ${ }^{1}$
} ADDITIONAL INDEX WORDs. olive harvest, olive oil quality, physicochemical
parameters, sensory analysis, antioxidant compounds

SUMMARY. The production of high-quality virgin olive oil from traditional olive (Olea europaea L.) varieties with peculiar and differential characteristics is of great interest for the olive oil market. 'Castellana' is an autochthonous variety mainly located in the center of Spain. The aims of this study were 1) the characterization of 'Castellana' virgin olive oils and 2) the evaluation of the influence of fruit ripening degree on the oil quality to establish an optimum harvest time for 'Castellana' olives. A wide range of physicochemical and sensorial quality parameters were assayed in oils produced at four harvest times during three crop seasons. 'Castellana' oils could be classified into the extra virgin category at all ripening degrees studied. This variety provides well-balanced oils from the sensorial point of view with an optimum chemical composition. Nevertheless, fruit maturation had a strong effect in various quality parameters, especially total phenol content, total tocopherol content, sensorial quality, and to a lesser extent in fatty acid composition. Loss of antioxidants and decrease in sensorial quality take place during olive ripening, reducing the nutritional, sensorial, and commercial quality of virgin olives oils as the harvest is delayed. Results suggest that the production of optimal extra virgin olive oil requires that 'Castellana' olives should be harvested from the middle of November to the middle of December, coinciding with a ripening index between 3.1 and 4.1. These results are of great importance to the olive oil industry for improving the quality of virgin olive oils produced from 'Castellana'.

$\mathrm{V}$ irgin olive oil, the main dietary fat in Mediterranean countries, differs from other edible oils because of its healthy properties and sensorial qualities. It is a genuine fruit juice, containing a high level of natural antioxidants associated with a balanced fatty acid composition that gives rise to its recognized nutritional value. In the last few decades, virgin olive oil consumption has increased because of its nutritional and healthy characteristics (Owen et al., 2000) but also owing to its organoleptic properties (Rotondi et al., 2004).

However, the levels of major and minor compounds responsible for virgin olive oil quality depend on different factors, with the variety and the fruit ripening index (RI) among the most important ones (Boskou

Instituto Madrileño de Investigación y Desarrollo Rural, Agrario y Alimentario (IMIDRA), Carretera Nacional 2, Km 38,200, Finca El Encín, Alcalá de Henares, Madrid 28800, Spain

The authors acknowledge the financial support from Spanish INIA RTA2010-00097 project and the FPI INIA fellowship associated with the former project given to Carmen Mena.

${ }^{1}$ Corresponding author. E-mail: mangeles.perez. jimenez@madrid.org.

https://doi.org/10.21273/HORTTECH03845-17 et al., 2006). Several authors have characterized oils obtained from different olive varieties, showing how the variety define clearly the physicochemical and organoleptic profile of virgin olive oils (Baccouri et al., 2008; Beltrán et al., 2004, 2010; Benito et al., 2013; Gómez-González et al., 2011; Gómez-Rico et al., 2008; Jiménez Herrera et al., 2012; Salvador et al., 2001; Sánchez-Casas et al., 2004). This fact gives rise to a high diversity of virgin oils with unique

The RI of the fruit is another important factor that highly affects virgin olive oil quality. During ripening, and differential characteristics. several metabolic processes take place in olive drupes with subsequent variations of the chemical structure and concentration of some compounds (Ryan et al., 2002; Yousfi et al., 2006). These changes are reflected in the quality grade, sensory characteristics, oxidative stability, and nutritional value of the obtained product. The magnitude of these changes depends on the variety, climate, and growing conditions. Beltrán et al. (2005) suggested that most of the olive oil produced does not belong to the best commercial quality as the fruit has not been picked at the optimal harvest time. This fact illustrates the need to determine the best harvest time for each olive variety and growing area to obtain the highest quality of the oils. The production of high-quality virgin olive oils is essential to improve the competitiveness of the olive oil market as consumers become more interested in olive oil quality.

Several works have studied the influence of fruit ripening on olive oil quality (Baccouri et al., 2008; Beltrán et al., 2005; Bengana et al., 2013; Fuentes de Mendoza et al., 2013; Gómez-Rico et al., 2008; Gutiérrez et al., 1999; Jiménez et al., 2013; Salvador et al., 2001). Nevertheless, there is a lack of information on the chemical characteristics and behavior of some varieties that are sustained in restricted areas. This is the case of 'Castellana', also known as 'Verdeja', 'Asperilla', 'Manzanilla', or 'Común'. This variety is the most representative variety in the area of La Alcarria in Castilla-La Mancha and the second main variety in the region of Madrid. 'Castellana' is a medium productive variety that performs well in poor soils and cold areas, highly adapted to these olive-growing areas. This

\begin{tabular}{llll}
\hline $\begin{array}{l}\text { Units } \\
\text { To convert U.S. to SI, } \\
\text { multiply by }\end{array}$ & U.S. unit & SI unit & $\begin{array}{l}\text { To convert SI to U.S., } \\
\text { multiply by }\end{array}$ \\
\hline 29.5735 & $\mathrm{fl} \mathrm{oz}$ & $\mathrm{mL}$ & 0.0338 \\
0.3048 & $\mathrm{ft}$ & $\mathrm{m}$ & 3.2808 \\
3.7854 & gal & $\mathrm{L}$ & 0.2642 \\
25.4 & inch $(\mathrm{es})$ & $\mathrm{mm}$ & 0.0394 \\
0.4536 & $\mathrm{lb}$ & $\mathrm{kg}$ & 2.2046 \\
1 & $\mathrm{meq} / \mathrm{kg}$ & $\mathrm{mmol} \cdot \mathrm{kg}^{-1}$ & 1 \\
1 & $\mathrm{micron}(\mathrm{s})$ & $\mu \mathrm{m}$ & 1 \\
28.3495 & $\mathrm{oz}$ & $\mathrm{g}$ & 0.0353 \\
0.0075 & $\mathrm{oz} / \mathrm{gal}$ & $\mathrm{g} \cdot \mathrm{mL}^{-1}$ & 133.5265 \\
1 & $\mathrm{ppm}$ & $\mathrm{mg} \cdot \mathrm{kg}^{-1}$ & 1 \\
$\left({ }^{\circ} \mathrm{F}-32\right) \div 1.8$ & ${ }^{\circ} \mathrm{F}$ & ${ }^{\circ} \mathrm{C}$ & $\left({ }^{\circ} \mathrm{C} \times 1.8\right)+32$ \\
& & &
\end{tabular}


variety covers more than 33,000 ha of surface, mainly located in the center of Spain, in the provinces of Guadalajara and Cuenca. It is also predominant in the east of the Comunidad de Madrid and in La Roda in Albacete. 'Castellana' is mainly responsible for the protected designation of origin "Aceite de la Alcarria," representing $100 \%$ of its production. Moreover, this variety gives rise to the $20 \%$ of the virgin olive oil production in Madrid covered by the quality seal "Aceite de Madrid" guarantee of quality. These products are of great economic and social importance in these areas (Vergara, 2006).

Considering all these aspects, the aims of this study were 1) the physicochemical and sensorial characterization of 'Castellana' monovarietal virgin olive oils and 2 ) the evaluation of the influence of fruit ripening on the quality of the oils produced to establish an optimum harvesting time for 'Castellana'. This last objective is an important goal as most olives in the olive-growing areas studied are traditionally harvested at a late stage of maturity to obtain a high oil yield, underestimating frequently the oil quality.

In this study, a wide range of physicochemical and sensorial quality parameters were assayed in oils produced at four harvest times during three crop seasons, providing information about the characteristics of 'Castellana' monovarietal oils as well as about the impact of fruit ripening on the oil quality and yield.

\section{Materials and methods}

Olive samples. Olives of 'Castellana' were harvested in three consecutive crop seasons (2010-11, 2011-12, and 2012-13) in a representative grove from each of four different olive-growing areas of the region of Madrid where this variety is grown (Colmenar de Oreja, Villarejo de Salvanés, Valdelaguna, and Anchuelo). Samples of the four olive groves were collected at biweekly intervals from 15 Nov. to 31 Dec., at four ripening stages. These dates were selected according to the normal olive-harvesting period in the central region of Spain.

Within each olive-growing area, six to seven healthy olive trees were randomly selected, marked, and 3-5 $\mathrm{kg}$ of olives were handpicked per grove. In total, 48 samples of 'Castellana' olives were obtained.

RI. RI was determined on 100 olives randomly selected in each sample according to the method proposed by Uceda and Frías (1975), based on the evaluation of the olive skin and pulp colors. RI values range from 0 ( $100 \%$ intense green skin) to 7 (100\% purple flesh and black skin).

OIL EXTRACTION PROCESS AND INDUSTRIAL OIL YIELD. Olive oils were extracted within $24 \mathrm{~h}$ after harvest using the Abencor system (MC2 Ingenierías y Sistemas, Seville, Spain). The olives were crushed with a hammer mill and the paste was mixed at $26 \pm 1{ }^{\circ} \mathrm{C}$ for $30 \mathrm{~min}$ and then centrifuged at $1232.60 g_{\mathrm{n}}$ for $1 \mathrm{~min}$. The oil was separated by decantation, filtered, and stored at $4{ }^{\circ} \mathrm{C}$ in darkness using amber glass bottles before analysis.

The industrial oil yield was expressed as a percentage of fresh olive paste weight using the following equation:

$$
\text { Oil yield }=(V \times D / W) \times 100,
$$

where $V$ is the volume of olive oil obtained (milliliters), $D$ is the density of the olive oil $\left(0.915 \mathrm{~g} \cdot \mathrm{mL}^{-1}\right)$, and $W$ is the weight of olive paste used.

Physicochemical Quality PARAMETERS. Free acidity expressed as percentage of oleic acid, peroxide value expressed as milliequivalents of active oxygen $\left(\mathrm{O}_{2}\right)$ per kilogram of oil, and ultraviolet spectrophotometric indices $\left(K_{232}, K_{270}\right.$, and $\Delta K$ extinction coefficients) were determined following the analytical methods described in European Commission Regulation 2568/91 and later amendments [European Economic Community (EEC), $1991]$.

Sensory ANALYsis. Sensory analysis was performed by the "Panel de Catadores de Aceite de Oliva Virgen de la Comunidad de Madrid," according to the method described in European Commission Regulation 640/2008 (EEC, 2008). This method allows for the classification of virgin olive oils based on the detection of negative attributes (fusty/ muddy, musty, winey, rancid, wet wood, others) as well as the measurement of the intensity of three positive attributes (green or ripe fruity, bitterness, and pungency). The panel consisted of at least eight trained tasters that scored the descriptors on a normalized sheet (from 0 to 10 ).

Furthermore, to characterize the organoleptic profile of each oil sample, the panelists completed an additional advanced profile sheet which allowed the evaluation of other sensory descriptors (green notes-grass or leaf-astringent, sweet, apple, almond, artichoke, tomato, others) as well as to assign to the samples a global score to compare the sensory quality of the oils. This global score takes into account the presence and intensity of the positive attributes and other factors as the complexity, persistency, and harmony of the oils that must be considered to establish the global organoleptic quality of a virgin olive oil. Thus, oil samples obtained scores ranging from 0 (minimum quality) to 100 ( $\mathrm{max}^{-}$ imum quality) (Vergara et al., 2007).

FatTy acid composition. The fatty acid composition of the oils was determined by gas chromatography (GC) as fatty acid methyl esters (FAMEs). FAMEs were prepared by saponification/methylation with sodium methylate according to European Commission Regulation (EC 2568/91). A chromatographic analysis was performed in a GC (6850 series II Network GC system; Agilent Technologies, Palo Alto, CA) equipped with a $60 \mathrm{~m} \times 0.25 \mathrm{~mm} \times 0.20$ $\mu \mathrm{m}$-film thickness fused capillary column (Supelco 24111; Sigma-Aldrich, St. Louis, MO) coupled to a flame ionization detector. Samples were introduced into the column at $170{ }^{\circ} \mathrm{C}$ during $30 \mathrm{~min}$. After this time, the temperature was increased $5{ }^{\circ} \mathrm{C} \cdot \mathrm{min}^{-1}$ to $200{ }^{\circ} \mathrm{C}$ and maintained for $12 \mathrm{~min}$. The flow rate of helium, used as a carrier gas, was $0.5 \mathrm{~mL} \cdot \mathrm{min}^{-1}$. Injector and flame ionization detector temperatures were 230 and $250{ }^{\circ} \mathrm{C}$, respectively. FAMEs were identified by comparing their retention times with those of standard compounds (Supelco 37 Component FAME Mix; SigmaAldrich).

Fatty acid composition was calculated as the percentage of total fatty acids, after their conversion to methyl esters, according to European Commission Regulation 2568/91 (EEC, 1991). 
Sterol composition. The determination of sterol composition was carried out by GC according to the official method described in European Commission Regulation 2568/91 (EEC, 1991). Quantification was made by addition of an internal standard $(\alpha$-cholestan- $3 \beta$-ol $\geq 95 \%$; Sigma-Aldrich) and apparent $\beta$-sitosterol was calculated as the sum of $\beta$-sitosterol, clerosterol, sitostanol, $\Delta 5$-avenasterol, and $\Delta 5,24$ stigmastadienol.

Total phenols content. Total phenolic compounds were determined after methanol extraction and subsequent reaction with Folin-Ciocalteu reagent and measured at a wavelength of $725 \mathrm{~nm}$ (Vázquez-Roncero et al., 1975). Results are expressed as milligrams of caffeic acid equivalents per kilogram of oil.

TOTAL TOCOPHEROL CONTENT. The determination of ( $\alpha$-tocopherols and $\gamma$-tocopherols) was carried out by high-performance liquid chromatography according to the International Union of Pure and Applied Chemistry method (IUPAC, 1992).

Oxidative stability. Test was performed using the Rancimat equipment at $98{ }^{\circ} \mathrm{C}$ (Metrohm, Herisau, Switzerland) with a continuous air flow of $10 \mathrm{~L} \cdot \mathrm{h}^{-1}$ and $2.5 \mathrm{-g}$ oil samples. The inflection point of the curve was assigned as the induction time, measured in hours (Koprivnjak et al., 2008).

Pigments (CHLOROPHylls AND CAROTENOIDS) AND CHROMATIC COORDINATES. Carotenoids and chlorophylls were determined at a wavelength of 470 and $670 \mathrm{~nm}$, respectively, in cyclohexane, according to the method of Mínguez-Mosquera et al. (1991). The concentrations of chlorophyll and carotenoids were expressed as milligrams of pheophytin and lutein per kilogram, respectively.

Chromatic coordinates were measured by the software Cintral to obtain the color according to the CIEL $a^{*} b^{*}$ method (Moyano et al., 2008).

STATISTICAL ANALYSIs. The statistical analysis was performed using SPSS statistical package (version 16.0 for Windows; IBM Corp., Armonk, NY). The level of significance of differences between mean values was determined at $5 \%$ by one-way analysis of variance, using the Tukey's test. The Pearson productmoment correlation test was used to verify correlations among variables.

\section{Results and discussion}

Olive RI AND OIL YIELD. Mean values of RI and industrial oil yield obtained at each harvest time are shown in Table 1.

Fruit color serves as a common marker for maturation level, expressed as RI. In the studied samples, RI of 'Castellana' olives increased from 3.10 in the fruit harvested at middle of November to 4.40 in the fruit collected at the end of December, showing a medium maturation pattern in relation with other varieties studied in the central region of Spain (Olivero-David et al., 2014; Salvador et al., 2001). The RI increased until the third ripening stage (middle of December), with a slight nonsignificant increase from this date. In agreement with other authors (Yousfi et al., 2006), a later harvesting date only assures the fruit remained longer on the tree but does not guarantee a higher degree of maturity than those olives harvested before.

Industrial oil yield, an important parameter for the grower, also increased during olive ripening ranging between $12.14 \%$ and $15.48 \%$, with an average value of $14.03 \%$, showing that 'Castellana' is a variety with a medium industrial yield in relation to other olive varieties (Tous et al., 2005). The increase in industrial oil yield is related to the loss of moisture of the olives as they mature. Nevertheless, in our study, a low correlation was found between RI and oil yield $(r$ $=0.37, P<0.01)$. A significant increase in industrial oil yield per tree during olive maturation has been also reported in different olive varieties studied (Benito et al., 2013; Gutiérrez et al., 1999; Jiménez et al., 2013; Salvador et al., 2001).

Table 1. Ripeness index and industrial oil yield obtained from 'Castellana' olives in relation to harvest date. Results represent the mean values of three consecutive crop seasons (2010-11, 2011-12, and 2012-13).

\begin{tabular}{lcccc}
\hline Parameter $^{\mathrm{z}}$ & $\begin{array}{c}\text { Harvest 1 } \\
(\text { mean } \pm \text { SD })^{\mathrm{y}}\end{array}$ & $\begin{array}{c}\text { Harvest 2 } \\
(\text { mean } \pm \text { SD })^{\mathrm{y}}\end{array}$ & $\begin{array}{c}\text { Harvest 3 } \\
(\text { mean } \pm \text { SD })^{\mathrm{y}}\end{array}$ & $\begin{array}{c}\text { Harvest 4 } \\
(\text { mean } \pm \text { SD })^{\mathrm{y}}\end{array}$ \\
\hline $\begin{array}{c}\text { Ripeness index } \\
(\text { 0 to 7 scale })\end{array}$ & $3.10 \mathrm{a} \pm 0.83^{\mathrm{x}}$ & $3.68 \mathrm{ab} \pm 0.64$ & $4.10 \mathrm{~b} \pm 0.63$ & $4.40 \mathrm{~b} \pm 0.77$ \\
$\begin{array}{c}\text { Industrial oil } \\
\text { yield (\% oil })\end{array}$ & $12.14 \mathrm{a} \pm 2.21$ & $14.22 \mathrm{ab} \pm 2.11$ & $14.28 \mathrm{ab} \pm 3.54$ & $15.48 \mathrm{~b} \pm 2.39$
\end{tabular}

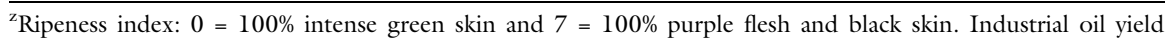
represents the weight of olive oil obtained from $100 \mathrm{~g}(3.53 \mathrm{oz})$ of olive paste.

${ }^{y}$ Harvest $1=15$ Nov., Harvest $2=1$ Dec., Harvest $3=15$ Dec., and Harvest $4=31$ Dec.

${ }^{x}$ Values followed by different letters at the same parameter are significantly different by one-way analysis of variance at the $5 \%$ level using the Tukey's test. 
Table 2. Physicochemical quality parameters of virgin olive oils obtained from 'Castellana' at four harvest dates. Results represent the mean values of three consecutive crop seasons (2010-11, 2011-12, and 2012-13). No statistical differences were found at $\mathbf{5 \%}$ by one-way analysis of variance and Tukey's test.

\begin{tabular}{|c|c|c|c|c|c|}
\hline Parameter $^{\mathrm{z}}$ & $\begin{array}{c}\text { Harvest } 1 \\
(\text { mean } \pm \text { SD })^{y}\end{array}$ & $\begin{array}{c}\text { Harvest } 2 \\
(\text { mean } \pm \text { SD })^{y}\end{array}$ & $\begin{array}{c}\text { Harvest } 3 \\
(\text { mean } \pm \text { SD })^{\mathrm{y}}\end{array}$ & $\begin{array}{c}\text { Harvest } 4 \\
(\text { mean } \pm \text { SD })^{\mathrm{y}}\end{array}$ & Avg \\
\hline Free acidity (\%) & $0.16 \pm 0.04$ & $0.18 \pm 0.06$ & $0.16 \pm 0.13$ & $0.16 \pm 0.08$ & $0.16 \pm 0.08$ \\
\hline$\left[\mathrm{O}_{2}(\mathrm{meq} / \mathrm{kg}\right.$ oil $\left.)\right]$ & $4.97 \pm 1.96$ & $4.47 \pm 1.51$ & $4.70 \pm 2.12$ & $4.61 \pm 1.65$ & $4.69 \pm 1.79$ \\
\hline$K_{270}$ & $0.138 \pm 0.027$ & $0.131 \pm 0.029$ & $0.121 \pm 0.036$ & $0.119 \pm 0.046$ & $0.127 \pm 0.036$ \\
\hline$K_{232}$ & $1.743 \pm 0.125$ & $1.662 \pm 0.137$ & $1.590 \pm 0.135$ & $1.564 \pm 0.135$ & $1.639 \pm 0.147$ \\
\hline
\end{tabular}

${ }^{\mathrm{z}}$ Free acidity represents the free fatty acids expressed as percentage of oleic acid. Peroxide index is expressed as milliequivalents of active oxygen per kilogram of oil $(\mathrm{l}$ meq $/ \mathrm{kg}=$ $\left.1 \mathrm{mmol} \cdot \mathrm{kg}^{-1}\right) . K_{232}$ and $K_{270}$ represent the ultraviolet spectrophotometric indices determined at 232 and $270 \mathrm{~nm}$, respectively. $\Delta K$ represents the increase in $K$ calculated as: $\Delta K=K_{m}-\left(\frac{K_{m-4}-K_{m+4}}{2}\right)$, where $K_{m}$ is the specific extinction at the wavelength for maximum absorption at $270 \pm 2 \mathrm{~nm}$.

${ }^{\mathrm{y}}$ Harvest $\mathrm{l}=15$ Nov., Harvest $2=1$ Dec., Harvest $3=15$ Dec., and Harvest $4=31$ Dec.

Table 3. Sensory parameters of 'Castellana' virgin olive oils obtained at four olive harvest dates. Results represent the mean values of three consecutive crop seasons (2010-11, 2011-12, and 2012-13).

\begin{tabular}{|c|c|c|c|c|c|}
\hline$\underline{\text { Sensory evaluation }}^{z}$ & $\begin{array}{c}\text { Harvest } 1 \\
(\text { mean } \pm S D)^{y}\end{array}$ & $\begin{array}{c}\text { Harvest } 2 \\
(\text { mean } \pm \mathrm{SD})^{\mathrm{y}}\end{array}$ & $\begin{array}{c}\text { Harvest } 3 \\
(\text { mean } \pm S D)^{y}\end{array}$ & $\begin{array}{c}\text { Harvest } 4 \\
(\text { mean } \pm S D)^{y}\end{array}$ & Avg \\
\hline Fruity $(0$ to 10 scale $)$ & $5.81 \pm 0.56$ & $5.96 \pm 0.44$ & $5.91 \pm 0.51$ & $5.73 \pm 0.76$ & $5.85 \pm 0.57$ \\
\hline Pungency (0-10 scale) & $4.53 \mathrm{a} \pm 0.77$ & $4.15 \mathrm{ab} \pm 0.40$ & $3.73 \mathrm{~b} \pm 0.73$ & $3.45 \mathrm{~b} \pm 0.81$ & $3.96 \pm 0.79$ \\
\hline Harmony (0-25 scale) & $15.88 \pm 2.71$ & $17.88 \pm 1.77$ & $17.43 \pm 2.61$ & $17.48 \pm 2.61$ & $17.17 \pm 2.49$ \\
\hline Complexity (0-10 scale) & $6.62 \mathrm{a} \pm 0.78$ & $6.74 \mathrm{a} \pm 0.52$ & $6.41 \mathrm{a} \pm 0.77$ & $6.00 \mathrm{~b} \pm 0.80$ & $6.44 \pm 0.76$ \\
\hline
\end{tabular}

${ }^{\mathrm{z}}$ Sensory analysis was performed according to the method described in European Commission Regulation 640/08 (European Economic Community, 2008).

${ }^{\mathrm{y}}$ Harvest $\mathrm{l}=15$ Nov., Harvest $2=1$ Dec., Harvest $3=15$ Dec., and Harvest $4=31$ Dec.

${ }^{\mathrm{x}}$ Values followed by different letters at the same parameter are significantly different by one-way analysis of variance at the $5 \%$ level using the Tukey's test.

Olive ripening has a high impact on the sensory quality of virgin olive oil, and is one of the most important factors to take into account to determine the best harvest time of each variety. In the studied monovarietals, fruity showed no significant variation and remain stable during olive ripening. However, bitterness and pungency were higher in oils obtained from less ripe olives, decreasing significantly through maturity process, diminishing from 4.1 to 2.6 in the case of bitterness and from 4.5 to 3.4 in the case of pungency. A falling trend was also found in green notes, decreasing from 5.3 to 4.0 during fruit ripening (data not shown). Significant negative correlations were observed between RI and bitterness and pungency $(r=-0.37, P=0.01$; $r=-0.50, P<0.01$, respectively).

The results obtained are in accordance with those carried out by different researchers in other olive varieties, reporting the influence of fruit ripening on the sensorial parameters, with a clear decreasing trend of the positive attributes as olives mature (Benito et al., 2013; Caporaso, 2016; Jiménez et al., 2013; Jiménez Herrera et al., 2012; Rotondi et al., 2010; Salvador et al., 2001).

The decrease in bitterness and pungency during ripening is related to the decrease in phenolic content and 0 -diphenols levels (Vossen, 2013), and follows the same trend as total phenol content as reported later. Nevertheless, results show that 'Castellana' oils are not excessively bitter or pungent even when they are obtained from green fruit. This fact is important from a commercial point of view as high levels of these positive attributes may be not accepted by some consumers (Caporaso et al., 2015).

The global score, a parameter that reflects the global organoleptic quality of the oils, remains stable until the third harvest (middle of December), decreasing from this date to a minimum value in the oils obtained in the last harvest. This fact shows the loss of sensory quality if the harvest is delayed. The complexity, which evaluate the number and intensity of aromas and flavors of a virgin olive oil, and the harmony or the balance between them were the parameters that more contribute to the global

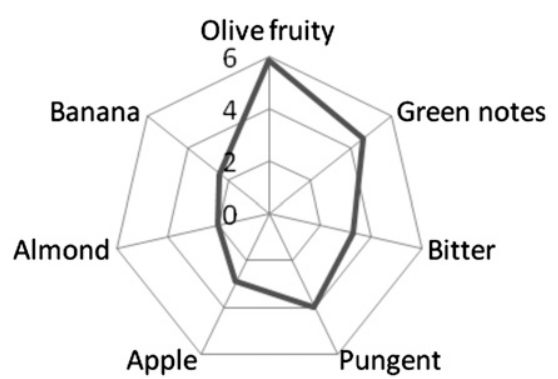

Fig. 1. Sensory profile of 'Castellana' virgin olive oils. Data represent average values of the oils obtained over the four harvest times studied in three consecutive crop seasons (2010$11,2011-12$, and 2012-13).

score $(r=0.87, P<0.05 ; r=0.70$, $P<0.05$, respectively), being an useful descriptors for virgin olive oil organoleptic quality.

Despite the variations in the sensory profile during olive ripening, 'Castellana' shows a wide optimal harvest time in relation to organoleptic quality as the oil samples maintained a good sensory quality from the middle of November to the middle of December (Vergara et al., 2007). 
FATTY ACID COMPosition. Fatty acid composition of olive oil is affected by different factors. This variation depends mainly on the olive variety, but also on the olive-growing area, climate, and the ripening stage at which the olives are harvested (Beltrán et al., 2004, 2005; Boskou et al., 2006; Gutiérrez et al., 1999; Salvador et al., 2001; Tous et al., 2005). So, the individual isolation and quantification of fatty acids present in olive oil has been used for characterization and quality evaluation of virgin olive oils.

Fatty acid profile of the different 'Castellana' monovarietal oils is reported in Table 4, with all the values within the legal limits established by European Commission regulation for extra virgin olive oil (EEC, 2013). The main fatty acids founded were oleic, palmitic, and linoleic acids, with mean values of $75.7 \%, 13.4 \%$, and $5.4 \%$. The high oleic acid content leads to an increase in oxidative stability, antihypertensive activity, and low-density lipoprotein (LDL) cholesterol-lowering effects (Psaltopoulou et al., 2004). Palmitoleic, stearic, and linolenic acids were also determined in small amounts in the oils, whereas margaric, margaroleic, arachidic, gadoleic, and lignoceric acids were present at less than $0.5 \%$.

Fatty acids are precursors of lipid oxidation, especially the polyunsaturated ones (Yun and Surh, 2012).
Consequently, the monitoring of their composition during maturation is of interest. With the exception of palmitic acid, the results showed no significant variation in fatty acid composition during olive ripening. Palmitic acid, the major saturated fatty acid in olive oils, decreased significantly from $14.3 \%$ to $12.9 \%$ between the first and the fourth harvest. This reduction of palmitic acid during olive maturation with the rest of fatty acids remaining stable is in agreement with the results described for different olive varieties of Tuscany (Italy) by Caselli et al. (1993). Gutiérrez et al. (1999) related this decline to a dilution effect caused by a constant quantity of palmitic acid but rising levels of total fatty acids resulting in a reduction in the relative amount of palmitic acid bound to the triglycerides.

Other works carried out in different olive varieties, besides a decrease in palmitic acid in the oils, reported variations in other fatty acids related to fruit ripeness, as an increase in oleic acid and/or linoleic acid in 'Picual' (Salvador et al., 2001), 'Chetoui' (Baccouri et al., 2008), 'Morisca' and 'Carrasqueña' (Fuentes de Mendoza et al., 2013), 'Souri' and 'Barnea' (Dag et al., 2011), 'Chemlal' (Bengana et al., 2013), and 'Arbequina' (Benito et al., 2013). This fact was supported by Gómez-González et al. (2011) and Vossen (2013), reporting that there is no clear trend in the variation of fatty acid with olive ripeness as different trends were found as a function of the ripeness state and the variety.

The oleic/linoleic ratio, the monounsaturated fatty acid/polyunsaturated fatty acid (MUFA/PUFA) ratio, and unsaturated fatty acid/saturated fatty acid ratio remain stable during fruit maturation, with mean values of $14.8,13.24$, and 5.06 , respectively. These values are high in relation to the those found in the literature for other monovarietal oils (Tous et al., 2005), pointing out a suitable fatty acid composition for 'Castellana' oils as these relationships are related to both nutritional and oxidative stability.

Sterol composition. Sterols are major constituents of the unsaponifiable fraction of olive oil. Their determination is an important tool to check authenticity and to detect adulterations of olive oil (Vichi et al., 2001). Moreover, profiles of these compounds can be used to classify virgin olive oils according to their fruit variety as sterol composition and total sterol content are affected by variety, crop year, fruit ripeness, storage time of fruit before oil extraction, processing, and also by geographic factors (Boskou et al., 2006; Giuffré and Louadj, 2013; Gutiérrez et al., 1999; Koutsaftakis et al., 1999; Salvador et al., 2001).

Sterol profile of 'Castellana' oils is shown in Table 5. According to the

Table 4. Fatty acid composition of virgin olive oils obtained from 'Castellana' at four harvest dates. Results represent the mean values of three consecutive crop seasons (2010-11, 2011-12, and 2012-13).

\begin{tabular}{|c|c|c|c|c|c|}
\hline Fatty acid composition $^{z}$ & $\begin{array}{c}\text { Harvest } 1 \\
(\text { mean } \pm \text { SD })^{y}\end{array}$ & $\begin{array}{c}\text { Harvest } 2 \\
(\text { mean } \pm S D)^{y}\end{array}$ & $\begin{array}{c}\text { Harvest } 3 \\
(\text { mean } \pm S D)^{y}\end{array}$ & $\begin{array}{c}\text { Harvest } 4 \\
(\text { mean } \pm S D)^{y}\end{array}$ & Avg \\
\hline Myristic acid (\%) & $0.01 \pm 0.00$ & $0.01 \pm 0.00$ & $0.01 \pm 0.00$ & $0.01 \pm 0.00$ & $0.01 \pm 0.00$ \\
\hline Palmitoleic acid (\%) & $1.23 \pm 0.21$ & $1.16 \pm 0.21$ & $1.10 \pm 0.09$ & $1.05 \pm 0.18$ & $1.13 \pm 0.18$ \\
\hline Margaric acid (\%) & $0.05 \pm 0.11$ & $0.05 \pm 0.01$ & $0.06 \pm 0.03$ & $0.06 \pm 0.03$ & $0.05 \pm 0.02$ \\
\hline Margaroleic acid (\%) & $0.10 \pm 0.03$ & $0.10 \pm 0.02$ & $0.10 \pm 0.00$ & $0.10 \pm 0.01$ & $0.10 \pm 0.02$ \\
\hline Linoleic acid $(\%)$ & $5.21 \pm 0.03$ & $5.57 \pm 1.33$ & $5.45 \pm 1.40$ & $5.54 \pm 1.14$ & $5.44 \pm 1.20$ \\
\hline Linolenic acid (\%) & $0.69 \pm 0.11$ & $0.71 \pm 0.08$ & $0.70 \pm 0.10$ & $0.68 \pm 0.11$ & $0.69 \pm 0.10$ \\
\hline Araquic acid (\%) & $0.39 \pm 0.07$ & $0.38 \pm 0.05$ & $0.38 \pm 0.07$ & $0.38 \pm 0.06$ & $0.38 \pm 0.06$ \\
\hline Gadoleic acid (\%) & $0.28 \pm 0.08$ & $0.24 \pm 0.05$ & $0.24 \pm 0.05$ & $0.25 \pm 0.05$ & $0.25 \pm 0.06$ \\
\hline Behenic acid (\%) & $0.10 \pm 0.00$ & $0.11 \pm 0.03$ & $0.10 \pm 0.00$ & $0.10 \pm 0.00$ & $0.10 \pm 0.01$ \\
\hline Lignoceric acid (\%) & $0.06 \pm 0.14$ & $0.05 \pm 0.01$ & $0.06 \pm 0.02$ & $0.05 \pm 0.01$ & $0.06 \pm 0.02$ \\
\hline
\end{tabular}

${ }^{\mathrm{z}}$ MUFA $=$ monounsaturated fatty acid; PUFA $=$ polyunsaturated fatty acid; UNSAT $=$ unsaturated fatty acid; SAT $=$ saturated fatty acid.

${ }^{y}$ Harvest $1=15$ Nov., Harvest $2=1$ Dec., Harvest $3=15$ Dec., and Harvest $4=31$ Dec.

${ }^{\mathrm{x}}$ Values followed by different letters at the same parameter are significantly different by one-way analysis of variance at the $5 \%$ level using the Tukey's test. 
current legislation (EEC, 2013), the analyzed oils have a sterol composition falling into extra virgin category.

The main sterols found are apparent $\beta$-sitosterol (the sum of $\beta$-sitosterol and four adjacent phytosterols: clerosterol, sitostanol, $\Delta 5$-avenasterol, and $\Delta 5,24$ stigmastadienol) and campesterol, with mean values of $94.9 \%$ and $2.8 \%$, respectively, values that fall within the legal limits established. High levels of apparent $\beta$-sitosterol are recommended for human health as phytosterols have a positive effect on reducing total plasma cholesterol and LDL cholesterol (St-Onge et al., 2003).

Stigmasterol is associated with various quality parameters for virgin olive oils. Thus, high levels of this sterol are correlated with high acidity and low organoleptic quality, whereas low levels suggest provenance from healthy fruit (Sánchez-Casas et al., 2004). In all the samples, the stigmasterol levels were low and below those for campesterol as is required by regulations.

The campesterol/stigmasterol ratio, previously used as an index of quality for olive oil (Koutsaftakis et al., 1999), provides additional information about processing conditions and their impact on oil quality. This relationship, used in combination with other quality parameters, could be useful to compare the quality of different oils produced from the same variety. In the samples studied, this ratio showed values greater than 3 along each one of the four harvest times, which highlights the healthiness of the olives and the good quality of the oils.

The total sterol content exceeded the established minimum limit (1000 $\mathrm{mg} \cdot \mathrm{kg}^{-1}$ ) for extra virgin category with a mean value of $1137 \mathrm{mg} \cdot \mathrm{kg}^{-1}$ in relation to other olive varieties (Boskou et al., 2006; Gutiérrez et al., 1999; Sánchez-Casas et al., 2004).

All the sterols and total sterol content remain stable during olive ripening in 'Castellana' oils. These results are in agreement with those reported by other authors (Kiritsakis, 1992), which did not find sterol variation in relation to fruit ripening. Nevertheless, a decrease in total sterols and $\beta$-sitosterol contents as olive matures has been reported in literature and observed in oils obtained from other olive varieties, such as 'Picual' and 'Hojiblanca' (Gutiérrez et al., 1999), 'Cornicabra' (Salvador et al., 2001), and Croatian varieties (Lukić et al., 2013). Fuentes de Mendoza et al. (2013) observed a decrease in apparent $\beta$-sitosterol associated with an increase in stigmasterol during ripening in oils obtained from the mixture of 'Morisca' and 'Carrasqueña', whereas total sterol content remain stable. The differences in the results could be explained by the differences in the sampling process. In the present work, the study was carried out from the middle of November to the end of December, covering a range of olive ripeness index from 3.10 to 4.40 . In previous studies, the maturity range evaluated is wider, starting the sampling in some cases on September, with an olive ripeness index near 0 . The evaluation of a wider range of ripeness covering almost all olive maturation process could allow observing the complete evolution of the sterol components during ripening.
Total phenol content. The phenolic compounds are natural antioxidants present in virgin olive oils that have a significant importance for their nutritional value and because of their influence on sensory characteristics and on the stability and shelf life of virgin olive oils. However, the levels of these compounds depend on different factors such us olive variety and ripeness, as well as some agronomic and technological aspects of production (Boskou et al., 2006).

'Castellana' monovarietal oils show medium-high levels of total phenolic compounds in relation to other olive varieties (Olivero-David et al., 2014; Tous et al., 2005), with a mean concentration of 356.4 $\mathrm{mg} \cdot \mathrm{kg}^{-1}$.

During maturation, the phenolic profile of olive fruit is significantly modified because of enzyme activity in a manner closely related to variety characteristics, with a constant reduction of oleuropein content that reach a minimum in overripe olives (Briante et al., 2002). 'Castellana' oils show high levels of total phenol compounds at early maturity with a mean value of $413.5 \mathrm{mg} \cdot \mathrm{kg}^{-1}$ that tends to decrease through the third ripening stage (middle of December). However, a significant fall in this antioxidants takes place from this date, diminishing to $248.3 \mathrm{mg} \cdot \mathrm{kg}^{-1}$ in the oils obtained from fruit collected at the end of December (Fig. 2). This fact gives rise to an important reduction on the nutritional and commercial quality of virgin olive oils as the harvest is delayed.

In addition to their antioxidant activity, phenolic compounds also contribute to virgin olive oil bitter and pungent taste (Bendini et al.,

Table 5. Sterol composition of 'Castellana' virgin olive oils obtained at four olive harvest dates. Results represent the mean values of three consecutive crop seasons (2010-11, 2011-12, and 2012-13). No statistical differences were found at 5\% by one-way analysis of variance and Tukey's test.

\begin{tabular}{|c|c|c|c|c|c|}
\hline Sterol composition $^{\mathrm{z}}$ & $\begin{array}{c}\text { Harvest } 1 \\
(\text { mean } \pm \text { SD })^{y}\end{array}$ & $\begin{array}{c}\text { Harvest } 2 \\
(\text { mean } \pm \text { SD })^{y}\end{array}$ & $\begin{array}{c}\text { Harvest } 3 \\
(\text { mean } \pm S D)^{y}\end{array}$ & $\begin{array}{c}\text { Harvest } 4 \\
(\text { mean } \pm S D)^{y}\end{array}$ & $\operatorname{Avg}^{y}$ \\
\hline Brassicasterol (\%) & ND & ND & ND & ND & ND \\
\hline Campesterol (\%) & $2.68 \pm 0.28$ & $2.88 \pm 0.38$ & $2.65 \pm 0.92$ & $2.89 \pm 0.55$ & $2.77 \pm 0.58$ \\
\hline Stigmasterol (\%) & $0.88 \pm 0.43$ & $0.81 \pm 0.38$ & $0.74 \pm 0.39$ & $0.83 \pm 0.53$ & $0.82 \pm 0.42$ \\
\hline$\beta$-sitosterol ap (\%) & $94.92 \pm 0.65$ & $94.92 \pm 0.79$ & $95.05 \pm 0.89$ & $94.79 \pm 1.19$ & $94.87 \pm 0.88$ \\
\hline Campesterol/stigmasterol (ratio) & $3.64 \pm 1.54$ & $4.53 \pm 2.64$ & $4.20 \pm 1.95$ & $4.30 \pm 1.59$ & $4.16 \pm 1.94$ \\
\hline
\end{tabular}

${ }^{\mathrm{z}} \mathrm{l} \mathrm{mg} \cdot \mathrm{kg}^{-1}=1 \mathrm{ppm}$

${ }^{\mathrm{y}}$ Harvest 1 = 15 Nov., Harvest 2 = 1 Dec., Harvest 3 = 15 Dec., Harvest 4 = 31 Dec.; and ND = not detected. 


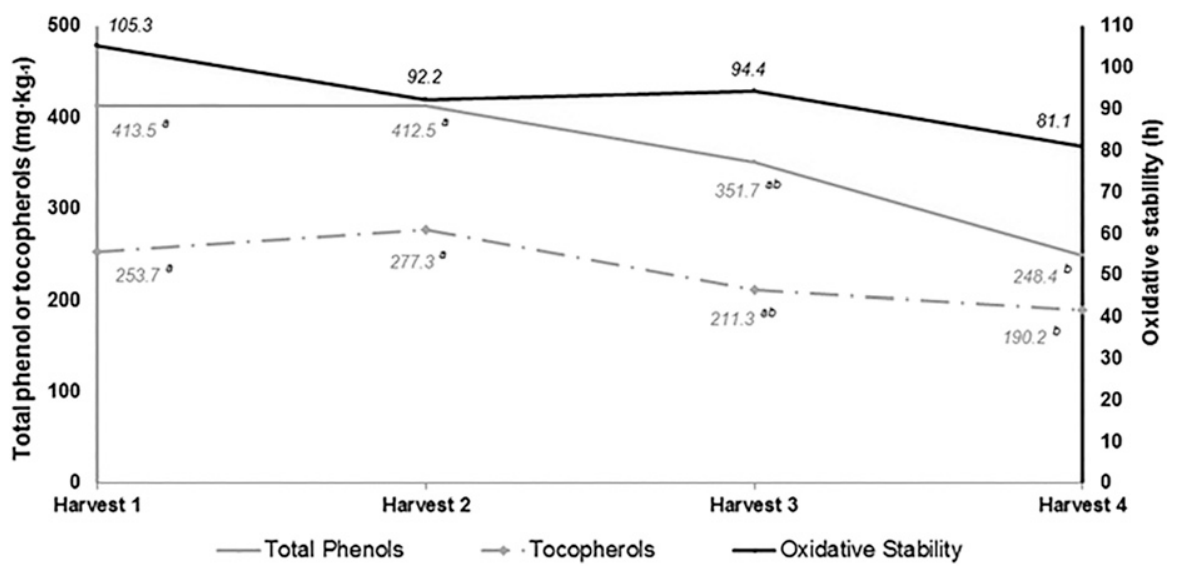

Fig. 2. Total phenol content, total tocopherol content, and oxidative stability at $98{ }^{\circ} \mathrm{C}\left(208.4^{\circ} \mathrm{F}\right)$ of virgin olive oils obtained from 'Castellana' at four harvest dates (Harvest 1 = 15 Nov., Harvest 2 = 1 Dec., Harvest 3 = 15 Dec., and Harvest $4=31$ Dec.). Data represent the mean values of three consecutive crop seasons (2010-11, 2011-12, and 2012-13). Values followed by different letters at the same parameter are significantly different by one-way analysis of variance at the $5 \%$ level using the Tukey's test; $1 \mathrm{mg} \cdot \mathrm{kg}^{-1}=1 \mathrm{ppm}$.

2007). Therefore, the loss in phenolic content during olive ripening may affect sensorial oil quality. Results confirmed that there is a moderate positive correlation between total phenolic amount and bitter and pungent intensities $(r=0.60, P<0.001$; $r=0.58, P<0.001$, respectively). Secoroids and orthodiphenolic compounds showed a high correlation with bitterness $(r=0.73, P<0.01$; $r=0.66, P<0.01$, respectively) but not with pungency. Consequently, the evolution of these two positive sensorial attributes throughout the maturation process followed the same trend as total phenol content (Table $3)$. The decrease in phenol compounds produces a loss on olive oil pungency and bitterness, turning the oils more soft and light, a fact that consumers could appreciate to a greater or lesser extend depending on the oils.

The reduction of phenolic compounds during olive maturation has been also reported by several authors in different monovarietal virgin olive oils (Baccouri et al., 2008; Beltrán et al., 2005; Bengana et al., 2013; Benito et al., 2013; Dag et al., 2011; Fuentes de Mendoza et al., 2013; Gutiérrez et al., 1999; Jiménez et al., 2013; Salvador et al., 2001).

Total tocopherol CONTENT. Tocopherols are natural antioxidants present in virgin olive oils appreciated for their vitamin $\mathrm{E}$ activity, of great nutritional interest, and for their contribution to the stability of virgin olive oils. The tocopherol content and composition is influenced mainly by the variety but also by other factors such as olive ripening stage and agroclimatic conditions (Baccouri et al., 2008; Beltrán et al., 2010; Gutiérrez et al., 1999).

'Castellana' monovarietal oils show medium levels of total tocopherols in relation to other olive varieties (Beltrán et al., 2010), with a mean content of $233.1 \mathrm{mg} \cdot \mathrm{kg}^{-1}$. The tocopherol content decreased in the oils as olive fruit ripened, ranging from $253.7 \mathrm{mg} \cdot \mathrm{kg}^{-1}$ in the oils obtained from fruit harvested at middle of November to $190.2 \mathrm{mg} \cdot \mathrm{kg}^{-1}$ in the oils obtained from fruit collected at the end of December (Fig. 2). As ripening progressed, tocopherol level shows a similar trend as the polyphenol content, with a significant decrease from the third ripening stage (middle of December) but remaining stable until this date. Nevertheless, the loss of tocopherols is less pronounced than the one of phenolic compounds. These results confirm the fact that the effect of the olive ripeness on the tocopherol content is not as critical as in the case of phenolic compounds (Bengana et al., 2013; Vossen, 2013).

The reduction of total tocopherol content during olive maturation has been also reported by several authors in different monovarietal virgin oils (Baccouri et al., 2008; Beltrán et al., 2005; Bengana et al., 2013; Benito et al., 2013; GómezRico et al., 2008; Gutiérrez et al., 1999; Salvador et al., 2001). Some authors reported that the decrease in $\alpha$-tocopherol during the ripening process is highly variety dependent (Beltrán et al., 2010).

These results, together with those previously reported for polyphenol content, highlight the effect of ripening on the antioxidant content and may help to establish the optimum fruit harvesting date for 'Castellana' oils according to their nutritional, sensorial, and commercial advantages.

Oxidative stability. Oxidative stability, although not considered a standard parameter of quality, is useful in providing information about the oil's shelf life and its commercial quality.

'Castellana' monovarietal oils show a mean oxidative stability of $94.5 \mathrm{~h}$, a high value that assures a good commercial quality for these oils. There are no significant differences in this parameter during the ripening process, although the values decreased slightly as fruit ripened and confirm that 'Castellana' oils are more sensitive to oxidation as the ripening process advances (Fig. 2). Similar results have been reported for 'Cornicabra' oils (Salvador et al., 2001) and for oils obtained from the mixture of 'Morisca' and 'Carrasqueña' (Fuentes de Mendoza et al., 2013). Some researchers have observed a progressive and significant decrease in the oxidative stability during maturity process for other monovarietals studied (Baccouri et al., 2008; Beltrán et al., 2005; Bengana et al., 2013).

The resistance to oil oxidative deterioration is usually attributed to two main reasons: the fatty acid profile and the minor compounds of antioxidant activity mainly constituted by polyphenols and tocopherols but also by chlorophylls and carotenoids. These contributions are corroborated by the moderate significant correlations found between oxidative stability and polyphenols $(r=0.44, P$ $<0.01)$, MUFA/PUFA ratio $(r=$ $0.51, P<0.01$ ), and oleic/linoleic acid ratio $(r=0.49, P<0.01)$. Poor correlations were obtained between oxidative stability and pigment contents. 
Although the contribution of phenols to the virgin olive oils stability was estimated to be higher than that of other compounds (Pellegrini et al., 2001), these results support the fact that $\approx 50 \%$ of the stability is contributed by polyphenols, mainly orthodiphenols (Gutiérrez et al., 1999; Papadopoulos and Boskou, 1991). Besides the single role of each antioxidant compound on the oil stability, the synergistic effect of minor compounds such as phenols, tocopherols, and pigments, together with the fatty acid composition, is responsible for the high oxidative stability in virgin olive oils (Bendini et al., 2007).

Pigments (CHLOROPHYLLS AND CAROTENOIDS) AND CHROMATIC COORDINATES. Chlorophyll and carotenoid pigments greatly influence the color of virgin olive oils, which is the first sensory attribute evaluated by consumers. Moreover, interest in food pigments is increasing because of their health benefits and antioxidant activity (Boskou et al., 2006).

Mean values of pigment contents and CIEL* $a^{*} b^{*}$ color parameters $\left(L^{*}, a^{*}, b^{*}\right)$ are shown in Table 6. 'Castellana' oils have medium levels of carotenoids and total pigment contents and high levels of chlorophylls in relation with those founded in other monovarietal oils (Baccouri et al., 2008; Benito et al., 2013; Salvador et al., 2001). According to the negative $\mathrm{a} / \mathrm{b}$ ratio, all the oils lie within the greenish-yellow color zone.

No significant differences were found in the pigment contents or color coordinates as olive fruit matured, although a downtrend is observed in carotenoid, chlorophyll, and total pigment contents in oils during ripening, with moderate negative correlations between $\mathrm{RI}$ and carotenoids $(r=-0.52, P<0.05)$, chlorophylls $(r=-0.53, P<0.05)$, and total pigment content $(r=-0.55$, $P<0.05)$. A trend of increase in $L^{*}$ value is also observed as the fruit ripened and decreased the pigment content. In fact, a high negative correlation was found between $L^{*}$ value and total pigment content $(r=-0.72$, $P<0.05)$ as the pigments would capture part of the light instead of transmitting it.

Similar results were observed by Motilva et al. (2000) in 'Arbequina' oils. Nevertheless, a significant decrease in pigment contents in virgin olive oil as olives mature has been reported in literature and described by different researchers in other olive varieties, such as 'Picual' and 'Hojiblanca' (Beltrán et al., 2005; Gutiérrez et al., 1999), 'Cornicabra' (Salvador et al., 2001), 'Hojiblanca', and Tunisian varieties (Bengana et al., 2013). As it has been indicated before, the differences in the results could be explained by the differences in maturity during the various sampling process. The evaluation of a wider range of ripeness in previous works could allow observing the complete evolution of the pigment contents during olive ripening.

\section{Conclusions}

This work reports the chemical and sensorial characterization of virgin olive oils obtained from 'Castellana' during four harvest dates and the changes in the different quality parameters through olive ripening. The study of the influence of fruit ripening on the oil quality is a key factor to establish the optimal harvest period for each variety to obtain the best quality according to the nutritional, sensorial, and commercial advantages.

'Castellana' oils could be classified into the extra virgin category at all ripening degrees studied. This variety provides well-balanced oils from the sensorial point of view with a suitable chemical composition. Nevertheless, fruit maturation had a strong effect in various quality parameters, especially total phenol content, total tocopherol content, sensorial quality, and to a lesser extent in fatty acid composition. A loss of antioxidants and a decrease in sensorial quality take place during olive ripening. This fact gives rise to a significant lowering of nutritional and commercial quality as harvest is delayed.

Based on these results, in our study conditions, the production of optimal extra virgin olive oil requires that 'Castellana' olives should be harvested from the middle of November to the middle of December, coinciding with an RI between 3.1 and 4.1. The loss of quality and the risk of significant frost in this area during the harvest time suggest that harvesting period for 'Castellana' should not extend beyond $15 \mathrm{Dec}$.

These results are of great importance to the olive oil industry for improving the quality of virgin olive oils produced from 'Castellana' as this variety is traditionally harvested at advanced stage of maturity looking for a high industrial oil yield without considering frequently the oil quality.

Table 6. Pigment contents and chromatic coordinates of 'Castellana' virgin olive oils obtained at four olive harvest dates.

Results represent the mean values of three consecutive crop seasons (2010-11, 2011-12, and 2012-13). No statistical differences were found at $5 \%$ by one-way analysis of variance and Tukey's test.

\begin{tabular}{|c|c|c|c|c|c|}
\hline Parameter $^{\mathrm{z}}$ & $\begin{array}{c}\text { Harvest } 1 \\
(\text { mean } \pm \text { SD })^{\mathrm{y}}\end{array}$ & $\begin{array}{c}\text { Harvest } 2 \\
(\text { mean } \pm \text { SD })^{\mathrm{y}}\end{array}$ & $\begin{array}{c}\text { Harvest } 3 \\
(\text { mean } \pm \text { SD })^{y}\end{array}$ & $\begin{array}{c}\text { Harvest } 4 \\
(\text { mean } \pm \text { SD })^{\mathrm{y}}\end{array}$ & Avg \\
\hline Carotenoids $\left(\mathrm{mg} \cdot \mathrm{kg}^{-1}\right)$ & $9.5 \pm 3.1$ & $9.9 \pm 3.3$ & $9.6 \pm 2.3$ & $9.0 \pm 4.0$ & $9.5 \pm 3.1$ \\
\hline Chlorophylls $\left(\mathrm{mg} \cdot \mathrm{kg}^{-1}\right)$ & $9.6 \pm 4.1$ & $8.9 \pm 5.0$ & $6.8 \pm 3.4$ & $7.3 \pm 6.1$ & $8.2 \pm 4.8$ \\
\hline Total pigments $\left(\mathrm{mg} \cdot \mathrm{kg}^{-1}\right)$ & $19.2 \pm 7.2$ & $18.8 \pm 8.1$ & $16.5 \pm 4.8$ & $16.3 \pm 9.9$ & $17.7 \pm 7.6$ \\
\hline Carotenoids/chlorophylls (ratio) & $1.08 \pm 0.36$ & $1.28 \pm 0.42$ & $2.04 \pm 2.17$ & $1.65 \pm 0.65$ & $1.51 \pm 1.18$ \\
\hline$L^{\star}$ & $87.39 \pm 4.28$ & $86.46 \pm 3.54$ & $88.58 \pm 4.28$ & $88.79 \pm 5.81$ & $87.85 \pm 4.45$ \\
\hline$a / b$ (ratio) & $-0.089 \pm 0.028$ & $-0.075 \pm 0.015$ & $-0.086 \pm 0.022$ & $-0.105 \pm 0.022$ & $-0.089 \pm 0.024$ \\
\hline
\end{tabular}

${ }^{\mathrm{z}} 1 \mathrm{mg} \cdot \mathrm{kg}^{-1}=1 \mathrm{ppm}$

${ }^{y}$ Harvest $1=15$ Nov., Harvest $2=1$ Dec., Harvest $3=15$ Dec., and Harvest $4=31$ Dec. 


\section{Literature cited}

Baccouri, O., M. Guerfel, B. Baccouri, L. Cerretani, A. Bendini, G. Lercker, M. Zarrouk, D. Daoud, and B. Miled. 2008. Chemical composition and oxidative stability of Tunisian monovarietal virgin olive oil regard to fruit ripening. Food Chem. 109(4):743-754.

Beltrán, G., M.P. Aguilera, C. del Rio, S. Sánchez, and L. Martínez. 2005. Influence of fruit ripening process on the natural antioxidant content of Hojiblanca virgin olive oils. Food Chem. 89(2): 207-215.

Beltrán, G., C. del Rio, S. Sánchez, and L. Martínez. 2004. Influence of harvest date and crop yield on the fatty acid composition of virgin olive oils from cv. Picual. J. Agr. Food Chem. 52(11):3434-3440.

Beltrán, G., A. Jiménez, C. del Rio, S. Sánchez, L. Martínez, M. Uceda, and M. P. Aguilera. 2010. Variability of vitamin E in virgin olive oil by agronomical and genetic factor. J. Food Compos. Anal. 23(6):633-639.

Bendini, A., L. Cerratani, A. CarrascoPancorbo, A.M. Gómez-Caravaca, A. Segura-Carretero, A. Fernández-Gutiérrez, and G. Lercker. 2007. Phenolic molecules in virgin olive oils: A survey of their sensory properties, health effects, antioxidant activity and analytical methods. An overview of the last decade. Molecules 12(8):1679-1719.

Bengana, M., A. Bakhouche, J. LorenzoSánchez, Y. Amir, A. Youyou, A. SeguraCarretero, and A. Fernández-Gutiérrez. 2013. Influence of olive ripeness on chemical properties and phenolic composition of Chemlal extra-virgin olive oil. Food Res. Intl. 54(2):1868-1875.

Benito, M., J.M. Lasa, P. Gracia, R. Oria, M. Abenoza, L. Varona, and C. SánchezGimeno. 2013. Olive oil quality and ripening in super-high-density Arbequina orchard. J. Sci. Food Agr. 93(9):22072220 .

Boskou, D., G. Blekas, and M. Tsimidou. 2006. Olive oil composition, p. 41-72. In: D. Boskou (ed.). Olive oil, chemistry and technology. AOCS Press, Champaign, IL.

Briante, R., M. Patumi, S. Limongelli, F. Febbraio, C. Vaccaro, A. Di Salle, F. La Cara, and R. Nucci. 2002. Changes in phenolic and enzymatic activities content during fruit ripening in two Italian cultivars of Olea europaea L. Plant Sci. 162(5):791-798.

Caporaso, N. 2016. Virgin olive oils: Environmental conditions, agronomical factors and processing technology affecting the chemistry of flavor profile. J. Food Chem. Nanotechnol. 2(1):21-31.

Caporaso, N., M. Savarese, A. Paduano, G. Guidone, E. De Marco, and R. Sacchi. 2015. Nutritional quality assessment of extra virgin olive oil from the Italian retail market: Do natural antioxidants satisfy EFSA health claims? J. Food Compos. Anal. 40:154-162.

Caselli, S., G. Modi, F. Nizzi, and P. Fiorino. 1993. Variabilidad en la composición en ácidos grasos, en esteroles y en alcoholes del aceite de oliva de cultivares de Toscana. Olivae 47:46-51.

Dag, A., Z. Kerem, N. Yogev, I. Zipori, S. Lavee, and E. Ben-David. 2011. Influence of time or harvest and madurity index on olive oil yield and quality. Scientia Hort. 127(3):358-366.

European Economic Community. 1991. Commision regulation No. 2568/91. On the characteristics of olive oil and olive pomace and their analytical methods. Offic. J. European Community L248: 1-83.

European Economic Community. 2008. Commission regulation No. 640/08. Amending regulation No. 2568/91. Offic. J. European Community L178: 11-16.

European Economic Community. 2013. Commission regulation No. 1348/13. On the amending regulation No. 2568/ 91. Offic. J. European Community L295:57-77.

Fuentes de Mendoza, M., C. de Miguel Godillo, J. Marín Expósito, J. Sánchez Casas, M. Martínez Cano, D. Martín Vertedor, and M.N. Franco Baltasar. 2013. Chemical composition of virgin olive oils according to the ripening in olives. Food Chem. 141(3):2575-2581.

Giuffré, A.M. and L. Louadj. 2013. Influence of crop season and cultivar on sterol composition of monovarietal olive oils in Reggio Calabria (Italy). Czech J. Food Sci. 31(3):256-263.

Gómez-González, S., J. Ruiz-Jiménez, and M.D. Luque de Castro. 2011. Oil content and fatty acid profile of Spanish cultivars during olive fruit ripening. J. Amer. Oil Chem. Soc. 88(11):17371745 .

Gómez-Rico, A., G. Fregapane, and M.D. Salvador. 2008. Effect of cultivar and ripening on minor components in Spanish olive fruits and their corresponding virgin oils. Food Res. Intl. 41(8):433-440.

Gutiérrez, F., B. Jiménez, A. Ruíz, and M. A. Albi. 1999. Effect of olive ripeness on the oxidative stability of virgin olive oil extracted from the varieties Picual and
Hojiblanca and on the different components involved. J. Agr. Food Chem. 47(1):121-127.

International Union of Pure and Applied Chemistry. 1992. Regulation no. 2432. Standard methods for the analysis of oils, fat and derivatives. Pergamon, Oxford, UK.

Jiménez, B., A. Sánchez-Ortiz, M.L. Lorenzo, and A. Rivas. 2013. Influence of fruit ripening on agronomic parameters, quality indices, sensory attributes and phenolic compounds of Picudo olive oils. Food Res. Intl. 54(2):1860-1867.

Jiménez Herrera, B., A. Rivas, A. Sánchez-Ortiz, M.L. Lorenzo Tovar, and M. Ubeda Muñoz. 2012. Influencia del proceso de maduración del fruto en la calidad sensorial de aceites de oliva virgen de las variedades Picual, Hojiblanca y Picudo. Grasas Aceites 63(4):403-410.

Kiritsakis, A. 1992. El aceite de oliva. A. Madrid Vicente Ediciones, Madrid, Spain.

Koprivnjak, O.S., D. Skevin, S. Valic, V. Majetic, S. Petricevic, and U. Ljubenkov. 2008. The antioxidant capacity and oxidative stability of virgin olive oil enriched with phospholipids. Food Chem. 111(1):121-126.

Koutsaftakis, A., F. Kotsifaki, and E. Stefanoudaki. 1999. Effect of extraction system, stage of ripeness, and kneading temperature on the sterol composition of virgin olive oils. J. Amer. Oil Chem. Soc. 76(12):1477-1481.

Lukić, M., I. Lukić, M. Krapac, B. Slandoja, and V. Pilizota. 2013. Sterols and triterpene diols in olive oil as indicators of variety and degree of ripening. Food Chem. 136(1):251-258.

Mínguez-Mosquera, M.I., L. Rejano, B. Gandul, A. Higinio, and J. Garrido. 1991. Color-pigment correlation in virgin olive oil. J. Amer. Oil Chem. Soc. 68(5): 332-336.

Motilva, M.J., J.M. Tovar, M.P. Romero, S. Alegre, and J. Girona. 2000. Influence of regulated déficit strategies applied to olive trees (Arbequina cultivar) on oil and yield and oil composition during the fruit ripening period. J. Sci. Food Agr. 80(14):2037-2043.

Moyano, M.J., A.J. Melendez-Martínez, J. Alba, and F.J. Heredia. 2008. A comprehensive study on the colour of virgin olive oils and its relationship with their chlorophylls and carotenoids indexes (II): CIELUV and CIELAB uniform colour spaces. Food Res. Intl. 41(5):513-521.

Olivero-David, R., C. Mena, M.A. Perez, B. Sastre, S. Bastida, G. Márquez-Ruiz, and F.J. Sánchez-Muniz. 2014. Influence 
of Picual olive ripening on virgin olive oil alteration and stability during potato frying. J. Agr. Food Chem. 62(48):1163711646.

Owen, R.W., W. Mier, A. Giacosa, W.F. Hull, B. Spiegelhalder, and H. Bartsch. 2000. Identification of lignans as major components in the phenolic fraction of olive oil. Clin. Chem. 46(7):976-988.

Papadopoulos, G. and D. Boskou. 1991. Antioxidant effect of natural phenols in olive oil. J. Amer. Oil Chem. Soc. 68(9):69-671.

Pellegrini, N., F. Visioli, S. Buratti, and F. Brihenti. 2001. Direct analysis of total antioxidant activity of olive oil and studies on the influence of heating. J. Agr. Food Chem. 49(5):2532-2538.

Psaltopoulou, T., A. Naska, P. Orfanos, D. Trichopoulos, T. Mountokalakis, and A. Trichopoulou. 2004. Olive oil, the Mediterranean diet, and arterial blood pressure: The Greek European prospective investigation into cancer and nutrition (EPIC) study. Amer. J. Clin. Nutr. 80(4):1012-1018.

Rotondi, A., B. Alfei, M. Magli, and G. Pannelli. 2010. Influence of genetic matrix and crop year on chemical and sensory profiles of Italian monovarietal extra-virgin olive oils. J. Sci. Food Agr. 90(15):26412648.

Rotondi, A., A. Bendini, L. Cerratini, M. Mari, G. Lerker, and T. Gallina Toschi. 2004. Effect of olive ripening degree on the oxidative stability and organoleptic properties of cv. Nostrana di Brisighella extra virgin olive oil. J. Agr. Food Chem. 52(11):3649-3654.
Ryan, D., M. Antolovich, P.D. Prenzler, P. Robards, and S. Lavee. 2002. Biotrasformations of phenolic compounds in Olea europeae L. Scientia Hort. 92:147-176.

Salvador, M.D., F. Aranda, and G. Fregapane. 2001. Influence of fruit ripening on Cornicabra virgin olive oil quality. A study of four successive crop seasons. Food Chem. 73(1):45-53.

Sánchez-Casas, J., E. Osorio, A.M. Montaño, and M. Martínez. 2004. Sterol and erythrodiol + uvaol content of virgin olive oils from cultivars of Extremadura (Spain). Food Chem. 87(12):225-230.

St-Onge, M.P., B. Lamarche, J.F. Mauger, and P.J.H. Jones. 2003. Consumption of a functional oil rich in phytosterols and medium-chain triglyceride oil improves plasma lipid profiles in men. J. Nutr. 133(6):1815-1820.

Tous, J., A. Romero, and I. Díaz. 2005. Composición del aceite, p. 359-372. In: L. Rallo, D. Barranco, J.M. Caballero, C. Del Río, A. Martín, J. Tous, and I. Trujillo (eds.). Variedades de olivo en España. Junta de Andalucía, MAPA, Mundi-Prensa, Spain.

Uceda, M. and L. Frías. 1975. Trend of the quality and quantitative composition of olive fruit oil during ripening. Proc. Intl. Mtg. Olive Oil, Cordoba, Spain. p. 25-46.

Vázquez-Roncero, A., C. Janer, and M. L. Janer. 1975. Polifenoles naturales y estabilidad del aceite de oliva. Grasas Aceites 26:14-18.
Vergara, G. 2006. Sector oleícola de la Comunidad de Madrid: El aceite de oliva virgen, p. 49-78. In: G. Vergara and M.A. Pérez (eds.). El aceite de oliva de oliva virgen de Madrid, Instituto Madrileño de Investigación y Desarrollo Rural, Agrario y Alimentario (IMIDRA), Comunidad de Madrid, Spain.

Vergara, G., M. Palancar, and M.A. Pérez. 2007. El análisis sensorial como herramienta para caracterizar el aceite de oliva virgen de Madrid. Alimentaria 384: 90-91.

Vichi, S., L. Pízzale, E. Toffano, R. Bortolomeazzi, and L. Conte. 2001. Detection of hazelnut oil in virgin olive oil by assessment of free sterols and triacylglycerols. J. AOAC Intl. 84(5):15341541 .

Vossen, P. 2013. Growing olives for oil, p. 19-56. In: A. Aparicio and J. Harwood (eds.). Handbook of olive oil, analysis and properties. Springer, New York.

Yousfi, K., R.M. Cert, and J.M. García. 2006. Changes in quality and phenolic compounds of virgin olive oils during objectively describes fruit maduration. Eur. Food Res. Technol. 223(1): 117-124.

Yun, J.M. and J.H. Surh. 2012. Fatty acid composition as a predictor for the oxidation stability of Korean vegetable oils with or without induced oxidative stress. Prev. Nutr. Food Sci. 17(2):158-165. 